\title{
VALUE CREATION MODELS IN THE 3PL INDUSTRY: WHAT 3PL PROVIDERS DO TO COPE WITH SHIPPER REQUIREMENTS
}

\begin{abstract}
Purpose - The resources and mechanisms required to complete a value proposition are generally considered as crucial aspects in designing a company business model. However, research in the 3PL arena concerned with studying how 3PL providers define their value creation architecture to meet different shippers' requirements has so far been inadequate. This paper fills the gap, providing a detailed investigation on how the 3PL providers' capabilities and logistics expertise can add value to their shippers' processes.

Design/methodology/approach - A qualitative exploratory research was conducted involving, first, a systematic combining process to understand the main factors and operational strategies whereby 3PL providers can create value and build a comprehensive framework of their value creation architecture. Second, a qualitative survey was conducted on 44 leading 3PL providers operating in Italy to understand how these providers can organise themselves to create value for shippers.

Findings - The 3PL providers' value creation architecture is presented within a clear and comprehensive framework, together with 30 potential operational strategies that can be used by 3PL providers and the related factors that enable value to be created for shippers. Three main value creation models (Volume-oriented 3PL providers, Process-oriented 3PL providers and Innovation-oriented 3PL providers) are identified. The importance of the different factors enabling value creation is highlighted for each model, identifying the distinctive operational strategies and those adopted most frequently.

Practical implications - From a managerial perspective, 3PL providers will find these results useful for developing suitable strategies to compete on the market. From their side, shippers can understand and evaluate how 3PL providers are able to offer value to their logistics processes, allowing them to select the logistics partner who best fits their needs.

Originality/value - The present paper fulfils the identified need of examining the 3PL providers' business model in detail. A set of distinct value creation models are identified and thoroughly investigated to reveal the different competitive advantages available to shippers.
\end{abstract}

Keywords - 3PL Providers, Business Model, Value Creation Architecture, Operational Strategies.

Article classification - Research paper 


\section{Introduction}

Third Party Logistics (3PL) providers are primarily called upon to perform services that add more value to a shipper's business than the shipper would be able to achieve alone (Deepen et al., 2008; Berglund et al., 1999). This value can take in different perspectives and include multiple aspects, such as offering the service level agreed with shippers at minimum cost while dealing efficiently with the industry complexities (Min et al., 2013; Lieb and Bentz, 2005) or developing skills and expertise in operations with higher added value and shipper-tailored services (Selviaridis and Norman, 2015; Large et al., 2011; Yeung et al., 2006). 3PL providers can organise themselves in different ways to meet the shippers' requirements. For instance, they can combine loads from many closely-located suppliers (Rabinovich et al., 1999) to engender a sustainable competitive cost structure. Alternatively, 3PL providers can offer conceptual logistics skills, such as redesigning the distribution network to optimise the customer's service level and improve their supply chain (Wallenburg, 2009; Berglund et al., 1999). This kind of behaviour is typically linked to the company choice of adopting a specific business model.

A business model can be defined as a 'representation of a firm's underlying core logic and strategic choices for creating and capturing value within a value network' (Shafer et al., 2005, p. 202). These choices should be mutually supportive and internally consistent (Hedman and Kalling, 2003). As previously observed by Prockl et al. (2012), 3PL providers' business models entail at least two elements, these being 'value proposition', i.e. the competitive advantage offered by 3PL providers, something that shippers expect from a logistics outsourcing relationship, and 'value creation architecture', i.e. the resources and mechanisms required to accomplish the value proposition (Eisenhardt and Sull, 2001).

The present study refers to the broad research arena of the value creation architecture available to 3PL providers, exploring the resources and mechanisms underpinning the service they offer. As will be discussed in the literature review section, several authors recognise that a number of factors are important in enabling 3PL providers to add value to the shippers' business, such as economies of scale and learning economies (Hertz and Alfredsson, 2003; Berglund et al., 1999). At the same time, these authors also acknowledge that different operational strategies can come into play for the various factors. For instance, according to Berglund et al. (1999), 3PL providers can pursue economies of scale by running a single warehouse for several shippers or operating joint transport networks for a set of shippers.

Only a few contributions identified specific value creation models based on a combination of factors. For instance, Prockl et al. (2012) compared two different value creation models. One, named 'factory', allows the 3PL provider to compete on the market through economies of scale and high internal process efficiency, whereas the second, entitled 'lernstatt', relies on knowhow and a drive for innovation to generate better processes for shippers. The authors, however, omit to link the value creation models to the necessary operational strategies.

In general, no holistic framework has so far been developed to describe the value creation architecture of the 3PL providers' business models or to define the operational strategies involved and link them to the factors that add value to the shippers' business. Therefore, the 3PL providers' value creation models with their combination of factors and strategies need to be analysed through suitable research.

The aim of the present paper is to fill the gaps in literature with a twofold objective. The first involves investigating the operational strategies adopted by 3PL providers and looks at how they relate to the factors pursued that add value to the shippers' business. The second is to examine in depth the different value creation models used by 3PL providers, highlighting the distinctive operational strategies for each.

The remainder of the paper is organised as follows. The main literature on the topic is summarised in the next section, and the research objectives and methodology are then 
presented. The fifth section contains the main findings and the interpretations of the results. The conclusions are finally drawn, with suggestions for future research.

\section{Literature review}

Value creation in the 3PL industry: theoretical background

As already suggested by Selviaridis and Spring (2007) in their literature review, ResourceBased Theory (RBT, as per Penrose, 1959) and Transaction Cost Economics (TCE, as per Coase 1937; Williamson 1985) are the most widely adopted theories supporting the outsourcing of logistics and the value that can be created by 3PL providers. Other theories (such as agency theory) seem to refer to the exception rather than the rule.

TCE states that a company decision to outsource is based on minimising the sum of its transaction and production costs (Coase 1937; Williamson 1985), while according to RBT, 3PL providers enable shippers to access complementary resources and gain competitive advantage (Zacharia et al., 2011). The term 'resource' is used broadly and refers not only to tangible assets, such as equipment, facilities and location, but also to the intangible assets of expertise, knowledge and organisational assets.

Starting from these definitions, RBT expands the TCE perspective by assisting scholars in understanding whether and how 3PL providers can achieve a reduction in transaction costs, an aspect seen as potentially giving competitive advantage. According to RBT, certain resources fit better in certain organisations (Hedman and Kalling, 2003) and 3PL providers have to set their strategies coherently with their value propositions. Therefore, based on RBT, it is highly important to examine the range of resources that 3PL providers can exploit, as well as the link between these resources and the 3PL providers' models for creating value.

In line with this, it is crucial to set out the meaning given to the term 'value'. Since a 3PL is a service business (Prockl et al., 2012), the way in which it is provided - in parallel with any service - is affected by unique features like intangibility and perishability, making it relatively difficult to standardise, count and estimate (Sampson and Froehle, 2006; Bowen and Jones, 1986). It follows that traditional value creation models focused on the company output and on price may not be sufficient to understand the mechanism of value creation in this industry (Vargo et al., 2008).

Vargo and Lusch (2008) introduced an alternative view, which they called Service-Dominant (S-D) logic to explain the relationship between a company and its customers within the value creation process, especially in service industries, and the relative implications. According to this perspective, a service is defined as the competences (resources, knowledge and skills) being applied by one entity to the benefit of another and the ensuing value, the 'value-in-use', comes from applying these competences beneficially, and it is defined and co-created by customers rather than being an intrinsic part of the output. As the authors stated, there is no value until an offering is taken up. The S-D logic has been adopted in multiple contexts, such as learning and innovation (Mele, 2009), customer behaviour (Anderson et al., 2008), including in the 3PL industry (Lin et al., 2015), where Yazdanparast et al. (2010) show that S-D logic can be a powerful framework for studying the provision of logistics services and the consequent creation of value in the field of logistics. According to the authors, S-D logic may also support value creation logistics since, in the logistics industry, value derives from the resources, knowledge and skills that 3PL providers offer to shippers. This perspective suggests that 3PL providers should also consider shippers to be a resource, as they are actively involved in the process of providing a service and can contribute towards creating value. By being thoroughly aware of the shippers' needs and their processes, 3PL providers are likely to offer them more customised services. 


\section{PL providers' business model: value proposition}

The value proposition within a 3PL provider's business model essentially involves the competitive advantages that a 3PL provider can offer and, from the shippers' perspective, what they expect from a logistics outsourcing relationship (Prockl et al., 2012).

Well-established literature already exists on the value propositions that can be fulfilled through the 3PL providers' business models. The elements identified so far are substantially homogeneous, as previously noted by Wilding and Juriado (2004) and can be ascribed to the general objectives of outsourcing. The first set of advantages that shippers may achieve are inherent in the outsourcing choice. They include: focus on the core business, as outsourcing allows a company to reassess and redirect resources, e.g. typically to company core functions (Kremic, 2006); reduction in invested capital, as 3PL providers offer shippers the opportunity to turn fixed costs into variable costs, and not to lock capital unnecessarily into costly logisticsrelated assets, facilities or equipment (Selviaridis and Spring, 2007; Bolumole, 2003; Van Laarhoven et al., 2000; Sum and Teo, 1999); and 'strategic' flexibility increases, as 3PL providers facilitate the process of redesigning the logistics network, to include, for example, moving warehouse locations and thereby offering access to international distribution networks (Selviaridis and Spring, 2007; Skjoett Larsen, 2000).

At the same time, it is widely accepted that the acquisition of external competences, capabilities and expertise is the main - and perhaps most often cited - strategic reason for outsourcing (Wilding and Juriado, 2004; Quinn, 1999; Quinn and Hilmer, 1995). As Quinn (1999) highlighted, 3PL providers can develop greater knowledge, invest more in software and training systems and, given the wider range of customer interaction, can also become more innovative than their counterparts with internal skills only. These major skills allow 3PL providers to influence the shippers' logistics cost structure by providing them with a higher performance/cost ratio than the shippers would be able to attain independently (Berglund et al., 1999).

The possible advantages for shippers are:

- Increase in efficiency and/or reduction in operating costs, for instance, due to economies of scale achieved through an increase in volumes handled when working with a number of shippers (Bolumole, 2003).

- Increase in operational flexibility, where, through their expertise, 3PL providers are able to cope with variations in demand (Wilding and Juriado, 2004).

- Improvement in service level, in terms of reduced customer lead-time and higher quality of service (Selviaridis and Spring, 2007; Wilding and Juriado, 2004; Razzaque and Sheng, 1998).

- Development of new business areas or improvement to existing processes through innovation (Prockl et al., 2012; Quinn, 1999; Quinn and Hilmer, 1995).

3PL providers may not pursue these competitive advantages simultaneously. Indeed, as previously observed by Prockl et al. (2012), there is a conflict in goals, for instance, between offering the service level agreed with shippers at the minimum cost and introducing innovation or helping shippers to develop new business areas. Hence, 3PL providers have first to choose the value proposition they intend to pursue and then select their value creation architecture accordingly.

\section{PL providers' business model: value creation architecture}

As mentioned above, some of the advantages offered by a 3PL provider in its value proposition come from the competences, capabilities and logistics expertise that it has developed over time. This means that there must be consistency between the value proposition and the value creation architecture. 
Looking at the required skills for 3PL providers that fit with a specific value proposition, the extant literature often focuses on a number of factors that create value for shippers. For instance, Berglund et al. (1999) stated that 3PL providers can add value to the shippers' business in four ways: operational efficiency - for instance by consolidating freight forwarding; coordination among shippers - for instance, sharing resources (such as warehouses) among several shippers; horizontal integration with other 3PL providers - through, for example, alliances and networks; and integrated management of the supply chain - for instance by introducing cross-docking facilities. Conversely, Hertz and Alfredsson (2003) analysed 3PL providers according to their customer coordination (i.e. problem solving) and customer adaptation abilities, proposing four types of 3PL providers based on the factors pursued: standard 3PL providers, service developers, the customer adapters and the customer developers. Standard 3PL providers shape their offer through highly standardised modular systems, creating value from the learning economies that underpin replicating an operation for multiple shippers. Service developers tend to focus on customer coordination, so they build their competitiveness mainly by creating economies of scale and scope. Customer adapters customise solutions for each customer, concentrating of improving the efficiency of the shippers' process. Customer developers balance customer coordination and adaptation by exploiting know-how and the methods and knowledge acquired in the field over time.

More recently, Prockl et al. (2012) identified and compared two main 3PL provider business models, 'factory' versus 'lernstatt'. The factory model competes on the market through highly standardised and centralised procedures to gain economies of scale and a high level of internal process efficiency, while the lernstatt model employs additional know-how and a drive for innovation to generate better processes for shippers.

Summarising the evidence that emerged from examining the literature on this research stream, a 3PL provider can create value through four factors, which are economy of scale/scope, learning economies, the ability to introduce innovation and flow management capabilities.

A brief description of each factor, as well as the main references, are reported in Table 1.

\section{XXXXXXXXXXXXXXXXXXXXXXXXXXXXXXXXXXXXXXXXXXXXXXXXXXXXXXXXX}

Take in Table 1

\section{XXXXXXXXXXXXXXXXXXXXXXXXXXXXXXXXXXXXXXXXXXXXXXXXXXXXXXXXX}

According to the literature, the factors described above are important pillars in any value creation architecture used by a 3PL provider, but value creation models based on a combination of these factors are recognised in only a few studies (e.g. Prockl et al., 2012). Moreover, each factor involved in the value creation architecture of a business model entails a range of underlying operational strategies for meeting the shippers' requirements. These operational strategies are, however, generally mentioned as examples, meaning that there is no comprehensive definition.

The topic is sufficiently important to have encouraged an increase in the number of contributions covering the specific operational strategies associated to the value creation architecture of the business models available to 3PL providers (e.g. collaboration and partnership with shippers as per Wang and Persson, 2016, continuous improvement as per Wallenburg, 2009 and horizontal integration as per Carbone and Stone, 2005). The analysis of these contributions in combination with the above-mentioned literature stream, led to 17 operational strategies being identified (Table 2), which can be employed by 3PL providers and can affect the shippers' logistics cost structure. 
Take in Table 2

\section{XXXXXXXXXXXXXXXXXXXXXXXXXXXXXXXXXXXXXXXXXXXXXXXXXXXXXXXXX}

For instance, by consolidating loads from multiple suppliers or distribution centres near to each other, a 3PL provider can achieve economies linked to full truckloads. This type of 'spatial integration' can also be achieved through frequent (e.g. on a daily basis) truckload trips delivering to shippers within the same geographic area (Rabinovich et al., 1999). Similarly, 3PL providers can make better use of their capacity by counterbalancing the peaks and troughs in the transport volumes offered by the various shippers, and 'backhauling' is often available (Hsiao et al., 2010).

In summary, the review conducted revealed that the topic is gaining academic attention, while the value creation architecture of the 3PL providers' business models has not been fully defined. This omission has also led to a potential misunderstanding of the role of 3PL providers, often seen as mere executors of logistics activities not performed in house, without considering the features of their offer.

\section{Research questions}

Starting from the above literature, the key aspects of the 3PL business model have been identified (these being value proposition and value creation architecture). The existing relationships between the different elements are summarised in Figure 1, highlighting the research focus of the present paper.

XXXXXXXXXXXXXXXXXXXXXXXXXXXXXXXXXXXXXXXXXXXXXXXXXXXXXXXXX

Take in Figure 1

\section{XXXXXXXXXXXXXXXXXXXXXXXXXXXXXXXXXXXXXXXXXXXXXXXXXXXXXXXXX}

Specifically, the aim of the current study is to address the gaps in literature explained above by examining the 3PL providers' value creation architecture from the RBT perspective. This theory sets out the factors underlying the strategic choices for providing shippers with a competitive advantage, i.e. creating value, and their relative features. According to the S-D logic, this value consists of applying the 3PL providers' resources to the benefit of shippers.

The objective of the study is twofold. The first aim is to build a comprehensive framework for the operational strategies that can be employed by 3PL providers, as well as looking at the relationship between the 3PL providers and the factors pursued to add value to the shippers' business. The second purpose is to gain a detailed understanding of the value creation models available to 3PL providers. The following research questions were identified:

- RQ 1: Which are the operational strategies that 3PL providers can pursue to increase the value of the shippers' logistics processes?

- RQ 2: What are the possible value creation models available to 3PL providers?

\section{Research methodology}

To answer RQ 1 and RQ 2, a two-phase methodology was adopted, as shown in Figure 2. Phase I entails identifying a framework relating to the 3PL providers' value creation architecture. 
Based on the results of Phase I, the value creation models used by 3PL providers were identified in Phase II.

\section{XXXXXXXXXXXXXXXXXXXXXXXXXXXXXXXXXXXXXXXXXXXXXXXXXXXXXXXXX}

Take in Figure 2

XXXXXXXXXXXXXXXXXXXXXXXXXXXXXXXXXXXXXXXXXXXXXXXXXXXXXXXXX

\section{Research process}

A 'systematic combining' process based on abductive logic (Kirkeby, 1994) was carried out to determine an inclusive framework for the value creation architecture of 3PL providers (Phase I). 'Systematic combining' is a process whereby theoretical framework, empirical fieldwork and case analysis evolve simultaneously, and it is particularly useful in the refinement of existing theories (Dubois and Gadde, 2002). A prominent feature of this approach is the constant reflection between the theoretical framework (such as in the extant academic literature) and practice (in, for example, evidence emerging from interviews). In line with the systematic combining approach, the process started by reviewing the literature on the topic, presented above, to identify the main factors and operational strategies that enable 3PL providers to create value within the investigation area. This step produced an initial framework of the value creation architecture for 3PL providers. Four pilot interviews were then conducted targeting 3PL providers operating in Italy, to adjust the framework by including the industrial viewpoint. The interviews confirmed the operational strategies that had emerged from the literature and helped identify several additional significant strategies which had not been included previously. The initial framework was successively modified following the empirical findings and the theoretical insights gained during the process.

The resulting framework of the 3PL providers' value creation architecture was used as an input for Phase II. An exploratory qualitative survey targeting 3PL providers operating in Italy was conducted to gather useful insights on how 3PL providers can organise themselves to create value for shippers.

A qualitative survey is a method for defining and investigating variations in population (Jansen, 2010; Fink, 2003). These surveys are used to determine how topics of interest within a given population differ and establish the meaningful variations within that population, without however inferring any statistical representation. This term is rarely used with this type of research being widely known as a 'qualitative study' (e.g. Prockl et al., 2012). A qualitative survey is similar to a multiple case study research, although there are differences in terms of data sources and time span. Qualitative surveys also differ from statistical surveys in terms of the formal object (i.e. diversity versus frequency distribution) and sample selection (like diversity, by purpose versus probability, by chance), an aspect highlighted by Jansen (2010).

\section{Sample selection}

As per Phase I, the sample selection was based on a theoretical sampling to collect information supporting the development of the framework. The selection process included companies under domestic and foreign ownership with annual revenues of between $€ 50$ and $€ 300$ million operating in industrial and consumer fields. All the respondents were senior managers with more than ten years' experience in the field, as it was felt that this would ensure a strategic vision of the problem. The interviewees are described in Table 3.

\section{XXXXXXXXXXXXXXXXXXXXXXXXXXXXXXXXXXXXXXXXXXXXXXXXXXXXXXXXX}

Take in Table 3 
As per Phase II, the sample was selected through a non-probability sampling framework, using a convenience sampling based on the database supplied by the Observatory for Contract Logistics (http://www.contractlogistics.it). The database contained 110 3PL providers with $€ 10$ million plus revenues operating in Italy.

\section{Data collection and data analysis}

In Phase I, data were collected through unstructured interviews, a method chosen because of the importance of gaining a thorough understanding of the interviewees' perspective (Bryman and Bell, 2011). The interviews varied in length, but on average were over one hour long. The framework was submitted to the interviewees in advance and then discussed, to draw a complete a picture as possible.

Data analysis was based on the procedures of grounded theory (Glaser and Strauss, 1967), an approach used for studying complex phenomena in the early stages (Glaser and Strauss 1967). The output consists of a set of integrated conceptual hypotheses organised around core categories. Starting from the stages proposed by Glaser and Strauss (1967), the following steps were identified:

- Coding: data were collected and coded (through an open coding procedure, as per Bryman and Bell, 2011) to generate concepts, categories and properties (the attributes or aspects of each category).

- Constant comparison: a constant transition backwards and forwards between the concepts and literature helped to maintain a close correlation between data and concept.

- Categories saturation: since data was collected according to the theoretical saturation principle, categories were saturated during the coding process.

By adopting this procedure, the information gathered from four interviews was eventually considered as adequate for the purposes of the present research, and no additional interviews were deemed to be necessary.

In Phase II, semi-structured interviews were chosen following Prockl et al. (2012), considered as the most effective way to explore the answers deemed to be the most interesting, collect insights and examples and ensure that the data were comprehensively understood.

An interview guideline with six main sections was developed. Section 1 dealt with general information about the company (the company profile in terms of type of ownership and balance sheet data, such as annual revenues). Section 2 was used to investigate the factors that help the 3PL providers to create value. Respondents were asked to indicate four such factors and rank them by importance, explaining the reasoning behind their ranking. The operational strategies adopted for each factor were investigated in Sections 3 to 6, respectively. Respondents were asked to indicate the operational strategies pursued, providing practical examples. Companies were contacted by e-mail to ask whether they could be interviewed. A covering letter was sent with the e-mail explaining the purposes of the study. The interviews carried out for this section lasted around half an hour and were structured so that cross-case comparisons could be made. A total of 44 companies consented to be interviewed, a $40 \%$ response rate.

The companies were then clustered according to the relative importance assigned to the factors enabling value creation. This helped identify the different value creation models that 3PL providers can employ.

The four initial unstructured interviews and the 44 semi-structured interviews were all carried out by phone to ensure that answers were coherent and so reliable. Because of the sensitive nature of the topic, confidentiality was ensured, and neither companies nor individuals are named.

\section{Quality guidelines}


Concerns regarding validity, reliability and generalisation are particularly important in qualitative research (Ellram, 1996; Yin, 1994). Leung's guidelines (2015) were followed to ensure that the quality of the research method was of an adequate level.

The validity (that is, the 'appropriateness of the tools, processes and data') of the research was ensured by constantly measuring the extant academic literature against the evidence that emerged from the pilot interviews, as well as by the sampling procedures adopted in the research. The informants received a copy of the interview guidelines before their interviews, so they knew which questions would be asked and the documentation needed. All the interviews were recorded and transcribed and the case reports were sent to the informants for verification, as an extra validation measure (Yin, 1994). Lastly, the interviews were structured so that an interview database could be created from all the key information (such as company profile, factor prioritisation and adoption level of each strategy), making cross-case analysis possible. Reliability (the 'replicability of the processes and the results') was secured through the accurate interview protocol and the interview database, and included the complete interview guidelines for each company and a detailed summary of the write-ups (Auramo et al., 2005). The interviews and the data analysis were all carried out by two researchers, with the interviews being held jointly and the data analysis being performed separately to ensure the reliability of the results.

Generalisation, which reflects how accurately the results reflect the topic under investigation, was possible because of the use of multiple sources used to build the constructs, the proper sampling procedures and the comprehensive data analysis. Following Yin (2014)'s recommendation, generalisation was enhanced by including different types of companies, an aspect that ensures adequate diversity in terms of annual revenue, company ownership and main industry sector.

\section{Findings and discussion}

3PL providers' value creation architecture: a framework

As illustrated in the section on methodology, the first result of this study was to design a framework for the 3PL providers' value creation architecture (Figure 3), presenting the four main factors enabling value creation (such as economies of scale, learning economies, ability to introduce innovation, flow management capabilities) and the related operational strategies.

\section{XXXXXXXXXXXXXXXXXXXXXXXXXXXXXXXXXXXXXXXXXXXXXXXXXXXXXXXXX}

Take in Figure 3

\section{XXXXXXXXXXXXXXXXXXXXXXXXXXXXXXXXXXXXXXXXXXXXXXXXXXXXXXXXX}

Thirty different operational strategies were identified overall. It is interesting to note that the same strategy can be used for more than one factor. For instance, specialisation in a specific industry means that a 3PL provider can pursue both economies of scale and learning economies. The increase in volumes handled within a specific industry allows a 3PL provider to operate efficiently by using resources intensively. At the same time, the knowledge and skills developed in a specific industry, which can then be replicated for multiple shippers, let 3PL providers achieve a performance/cost ratio that shippers would be unable to match by themselves.

As stated above, this conceptual framework was obtained from the literature review in combination with the pilot interviews with professionals involved in the research. Their contribution led to the inclusion of ten additional operational strategies that had not been mentioned in the literature ('PI' in Figure 3).

With regards to flexibility, alongside the well-known form of asset flexibility (i.e. sharing resources, such as personnel and equipment), two new facets of flexibility have emerged: 
shipper reallocation among multiple sites (such as 'asset flexibility') and dynamic routing (such as 'network flexibility'), i.e. the ability to allocate multiple routes to different loads usage dynamically, as reported in this statement by an expert in the sector:

'... A 3PL provider undoubtedly relies on its flexibility ['Flexibility'] to offer services. For example, they can use multiple routes or set up delivery methods dynamically ['Dynamic routing'] by developing a widespread network. They can also reallocate resources among multiple sites ['Warehouse staff reallocation among multiple sites'] or several clients across multiple sites ['Shipper reallocation among multiple sites']' (Company A, Head of Strategic Business Development)

Similarly, while the synergic management of shippers with complementary product seasonality is often cited in the literature, the pilot interviews showed that 3PL providers can also add value by exploiting other types of synergy, e.g. supply chain synergies, as observed in the statement below:

'One way to add value to our shippers is to manage the flow of shippers within the same supply chain synergistically ['Exploitation of supply chain synergies']. For example, one of our shippers operating in the retail industry introduced us to their suppliers: today all of their products (the shippers' and their suppliers') are located in the same distribution centre' (Company B, Business Development Director)

Another key element brought up by the experts relates to the role of partnerships and how they can introduce innovation. These partnerships can include shippers, technology providers and research institutes/consultancy companies. Two statements showing how 3PL providers can create value to their shippers' business by establishing partnerships are included below:

$\therefore$ A partnership with a consultancy company ['Partnership with research institutes or consultancy companies to introduce innovation'] has allowed us to introduce a pilot project to visit multiple shippers' distribution centres in a single trip' (Company B, Business Development Director)

'...We have developed a partnership to introduce innovative technology ['Partnership with shippers to introduce innovation'] for tobacco product authentication and traceability. It makes use of unique identification codes to be assigned to the smallest unit load (i.e. single package) ensuring that it can be traced along the entire supply chain and protects it from counterfeiting...' (Company D, Business Development Director)

Looking at the other four operational strategies added during Phase I (such as a process reengineering team focused on new customers' processes, executive training, market segment specialisation by type of shipper and staff training), the sector experts:

- Recognise the important role of process re-engineering teams, not only for supporting continuous improvement but also in terms of analysing and re-engineering new customers' processes (with ad hoc teams).

- Consider staff qualification and continuous training at all company levels as a key element in building competitive advantage; it follows that staff and executive training are considered to be strategies worth pursuing with competitiveness in mind.

- Recognise shipper-type specialisation (e.g. shippers using piece-picking) as a valuable specialisation strategy to create value, in addition to other recognised market segment specialisations (i.e. industry, sales channel and geographic area).

3PL providers' value creation models 
The findings highlight that 3PL providers can employ different value creation models, consistently with the results obtained by Prockl et al. (2012). Our study allowed us to identify three main groups, with different priorities assigned to the four factors enabling value creation (Figure 4).

\section{XXXXXXXXXXXXXXXXXXXXXXXXXXXXXXXXXXXXXXXXXXXXXXXXXXXXXXXXX}

Take in Figure 4

\section{XXXXXXXXXXXXXXXXXXXXXXXXXXXXXXXXXXXXXXXXXXXXXXXXXXXXXXXXX}

The first group - Volume-oriented 3PL providers - gives high importance to both economies of scale and flow management capabilities. The 3PL providers never allocated the lowest rating of ' 1 ' to these factors and always placed them among the most significant factors when setting their strategies.

While still giving high importance to flow management capabilities, the second group Process-oriented 3PL providers - tends not to exploit economies of scale, preferring instead the ability to introduce innovation, which can improve their ability to manage shippers' processes efficiently.

Conversely, the third group - Innovation-oriented 3PL providers - gives no importance to flow management capabilities but instead focuses on continuous improvement to the service through a combination of having the ability to introduce innovation and to exploit learning economies. Detailed company profiles and the results relating to the relative importance assigned by these three groups to the factors enabling value creation are reported in Tables 4, 5 and 6 .

XXXXXXXXXXXXXXXXXXXXXXXXXXXXXXXXXXXXXXXXXXXXXXXXXXXXXXXXX Take in Table 4

XXXXXXXXXXXXXXXXXXXXXXXXXXXXXXXXXXXXXXXXXXXXXXXXXXXXXXXXX XXXXXXXXXXXXXXXXXXXXXXXXXXXXXXXXXXXXXXXXXXXXXXXXXXXXXXXXX Take in Table 5

XXXXXXXXXXXXXXXXXXXXXXXXXXXXXXXXXXXXXXXXXXXXXXXXXXXXXXXXX

XXXXXXXXXXXXXXXXXXXXXXXXXXXXXXXXXXXXXXXXXXXXXXXXXXXXXXXXX

Take in Table 6

XXXXXXXXXXXXXXXXXXXXXXXXXXXXXXXXXXXXXXXXXXXXXXXXXXXXXXXXX

Distinctive features seem to emerge when analysing the operational strategies adopted by each group, reported in Table 7. Starting from these, it was then possible to identify the most distinctive operational strategies and those adopted most frequently for each value creation model. These results are summarised below, with a brief description and a practical example for each value creation model.

XXXXXXXXXXXXXXXXXXXXXXXXXXXXXXXXXXXXXXXXXXXXXXXXXXXXXXXXX Take in Table 7

XXXXXXXXXXXXXXXXXXXXXXXXXXXXXXXXXXXXXXXXXXXXXXXXXXXXXXXXX

Volume-oriented 3PL providers 
Volume-oriented 3PL providers typically build their competitive advantage on a combination of operational strategies which allow them to manage high volumes efficiently. It emerged that this value creation model is the model adopted most frequently within the considered sample (in 22 3PL providers out of 44), while process-oriented architecture and innovation-oriented architecture are more or less equally distributed between the remaining 3PL providers (in 27\% and $23 \%$ of the cases, respectively).

The development of operational planning abilities and forecasting planning tools are the strategies adopted most frequently ( $73 \%$ and $68 \%$, respectively), seen as the prerequisites for achieving efficiency goals. This group can be distinguished by having introduced multiproducer warehousing and making wide use of forecasting and planning tools (with an adoption level of $45 \%$ and $68 \%$ respectively, compared to $11 \%$ and $54 \%$ for the other groups), together with concentrating on specific market segments $(64 \%$ by industry, $23 \%$ by sale channel and $36 \%$ by type of shipper, compared to $59 \%, 9 \%$ and $9 \%$, respectively, for the other groups).

By introducing multi-producer warehousing, often in conjunction with a strong market segment specialisation, critical mass can be achieved, and a cost structure that would be difficult for an individual shipper. The increase in volumes handled inevitably leads to higher complexity and, hence, to the need for forecasting and planning tools.

With regards to the profile of the company in the group, achieving critical mass seems to relate only in part to the company' size, as the annual revenue of $50 \%$ of the sample is over $€ 100$ million. The importance given to economies of scale can be explained by the fact that companies in this group subcontract less - and accordingly use their own assets more compared to the other groups. Subcontracting is below $70 \%$ in more than $30 \%$ of the companies.

'We offer highly specialised logistics services to shippers operating in the grocery industry, especially retailers. We manage their warehousing and distribution. We usually deliver to the retailers' points of sale using our own high-capacity lorries. To reduce empty returns, we have backhauling agreements with various food producers close to the retailers' points of sale. We have also introduced a web-based booking system for loading/unloading time slots to reduce the trucks' waiting time at our warehouse' (Company 23)

\section{Process-oriented 3PL providers}

Process-oriented 3PL providers typically focus their offer on process improvement by continuously monitoring and benchmarking performance (67\% of cases) and pursuing supply chain synergies (58\%), for instance by managing shippers belonging to the same supply chain to optimise routes and maximise the loads handled.

The main feature of this group is that they establish alliances with other providers (horizontal integration) and standardise their processes (with an adoption level of $58 \%$ and $50 \%$, respectively, compared to a weighted average of $28 \%$ and $34 \%$ for the other groups).

It is also worth noting that process-oriented 3PL providers also differ from the other groups by supporting initiatives that involve their staff in the company strategy, although this practice is still relatively rare (such as stretch goals/assignments for human resources, with an adoption level of $33 \%$, compared to a weighted average of $19 \%$ for the other groups). These initiatives can be of different types and are intended to encourage managers and operational staff to be more proactive in developing and sharing knowledge and new valuable ideas on how the process can be improved and redesigned.

Looking at the company profile, $50 \%$ of the sample has annual revenues between $€ 50$ and $€$ 100 million, suggesting that critical mass can be achieved mainly through alliances than internally, as is reflected in the percentages presented.

Horizontal integration with other providers plays an important role, since Process-oriented 3PL providers often have no corporate strategy for developing their physical assets (such as a 
capillary network) and subcontracting is above $80 \%$ for almost all these companies. Process standardisation (which is the second distinctive strategy for Process-oriented 3PL providers) can be seen as a prerequisite for cooperating with other providers and so achieve greater efficiency.

'To control and improve warehousing operations, we have introduced a performance assessment system involving staff at different levels. The process involves both our customer's staff and those working in warehousing and distribution at subcontracted providers. We schedule daily meetings to discuss and solve operational problems and meet on a monthly basis to cover organisational issues. We monitor internal KPIs linked to continuous process improvement as well as the KPIs defined in our agreement.

We have also introduced what we call 'Ideal Management Process' to encourage staff involvement. This consists of gathering proposals on how to improve our processes from all the members of our company. Every year, we give a monetary prize to the best project' (Company 9)

\section{Innovation-oriented 3PL providers}

Innovation-oriented 3PL providers usually build their competitive advantage on the expertise gained through process re-engineering teams, focusing on both continuous improvement and new customers' processes (in $70 \%$ of the cases) and the related transfer of best practice $(70 \%)$. Best practice transfer is typically a structured process, normally involving regular meetings to identify various kinds of best practice and assess how they can be applied to other operational units.

This group pursues two distinctive operational strategies: shared Information Technology (IT) systems for multiple clients (which are systems for managing transport on behalf of multiple shippers and systems to optimise warehouse performance) and partnerships with shippers, with a $70 \%$ and $40 \%$ adoption level, respectively (compared to $47 \%$ and $18 \%$ for the other groups). An interesting point is that, alongside partnerships with shippers, IT systems are seen as a key tool for managing an innovation-oriented outsourcing relationship. Innovation-oriented 3PL providers differ from the others 3PL providers by introducing staff and executive training initiatives (50\% and $40 \%$ of the cases, compared with $24 \%$ and $15 \%$ for the other groups), which are seen as a fundamental element for developing the knowledge and managerial/technological skills that shippers would not be able to attain by themselves.

Foreign-owned companies seem to prefer this model for competing on the market, and they probably capitalise on the experience gained in the other countries. There is no specific pattern in the results for company size and subcontracting percentages.

'We have periodic meetings with our customers to discuss their possible needs concerning specific issues. By being aware of our shippers' problems and through our close partnerships with technology providers, we have recently been able to introduce two innovative solutions. We first introduced an automatic picking line to set up physical display units in large commercial centres. Using this solution, our customers can put off making decisions and adopt a postponement strategy.

The second project was to address our customers' need to increase their visibility along the entire supply chain, with specific focus on local distribution, even when subcontracted to small carriers. We therefore developed internally a mobile app integrated with our TMS. With this mobile app, carriers send us - and consequently our customers - proof of delivery in real time' (Company 8) 
Besides embracing operational strategies to pursue a specific value creation architecture, other commonly adopted strategies have also been found (such as the development of operational planning abilities and setting up a process re-engineering team). The latter point highlights the fact that 3PL providers tend to set up also 'complementary' strategies to compete on the market. These strategies can be seen as 'a must have' service offered to shippers, independently of the competitive advantage that shippers search for when outsourcing.

\section{Discussion}

As the results show, 3PL providers can pursue a number of factors and operational strategies to create value. The empirical work in Phase I highlighted several facets that were missing in the academic literature, such as exploiting supply chain synergies to achieve economies of scale, or introducing different categories and levels of employees to exploit learning economies. Starting from the resulting framework (addressing RQ 1), Phase II allowed us to identify three different value creation models (RQ 2).

Specifically, the results show that volume-oriented 3PL providers typically focus their offer on their ability to manage high volumes efficiently. Operational planning ability and forecasting and planning tools are seen as the prerequisite to reach this goal. The distinctive features are introducing multi-producer warehousing and a high focus on specific market segments. Comparing these results with the previous models that emerged from the literature, volumeoriented 3PL providers are similar to the 'factory' 3PL providers proposed by Prockl et al. (2012), as they propose a high level of standardisation and centralisation to compete on the market. To pursue their goals, volume-oriented 3PL providers tend to develop services to consolidate freight forwarding and coordination among shippers (such as the operational efficiency and coordination among shippers recorded by Berglund et al., 1999) and build their competitiveness mainly by creating economies of scale and scope, in accordance to the 'service developers' proposed by Hertz and Alfredsson (2003),

Process-oriented 3PL providers typically focus their offer on improving processes by continuously monitoring and benchmarking performance and pursuing supply chain synergies. As suggested by Berglund et al. (1999), these synergies come about by focusing on horizontal integration with other 3PL providers (through alliances and networks with other providers) and the integrated management of the supply chain - for instance, by managing shippers belonging to the same supply chain. Process-oriented 3PL providers shape their offer by using both standardised modular systems and solutions tailored for each industry, and develop dedicated services that - at a later stage - can be proposed to multiple shippers with similar needs. From this point of view, this type of 3PL providers will balance their customer coordination and adapt their offer to exploit the know-how, methods and knowledge acquired in the field over time, similarly to the customer developers proposed by Hertz and Alfredsson (2003).

Finally, innovation-oriented 3PL providers usually build their competitive advantage on the expertise they gained through process re-engineering teams, with focus on continuous improvement and new customers' processes and the relative transfer of best practice. Innovation-oriented 3PL providers are similar to the 'lernstatt' 3PL providers proposed by Prockl et al. (2012), as they compete on the market by relying on additional know-how and a drive for innovation to generate better processes for shippers. As this drive for innovation is often customised for the shipper, these 3PL providers can also be considered similar to the Customer Adapters proposed by Hertz and Alfredsson (2003).

\section{Research implications}


This study has implications at both academic and practical level. From an academic standpoint, this is a first attempt to offer a two-fold perspective. Concerning RQ 1, this question proposes a comprehensive characterisation of the 3PL providers' value creation architecture, including a complete overview of the pursuable strategies. In this perspective, this contribution can be seen as an extension of previous studies on factors enabling 3PL providers to create value (e.g. Berglund et al. 1999). These studies mainly explore the link between several strategies and a number of factors that lead towards creating value for the shippers' business, without converging to a common and inclusive view. Looking at RQ 2, starting from the proposed value creation architecture framework, this study investigates the 3PL providers' value creation models in depth, focusing on their associated operational strategies. The findings first corroborate the work by Prockl et al. (2012) by proposing value creation models that take multiple factors into account and using a larger sample of 3PL providers. These findings are supplementary to this piece of literature as they relate the value creation models to the required operational strategies required to accomplish them.

From a practitioner standpoint, this thorough analysis of the 3PL providers' value creation models has significant potential for supporting the strategic decisions taken by both 3PL providers and shippers. Indeed, shippers can evaluate in what way 3PL providers can offer value and improve the shippers' logistics processes. This evaluation - which implies a thorough awareness of 3PL providers' value creation mechanisms - is crucial for selecting the logistics partner that fits the shippers' needs best. For instance, shippers wishing to improve the efficiency of their processes should look for 3PL providers who base their offer on the efficient management of high volumes (by pursuing strategies to share resources among different shippers). Conversely, shippers wishing to achieve process effectiveness and/or improvement should look for 3PL providers working on process re-engineering and problem solving to offer more tailored solutions (by introducing process re-engineering teams or structured processes for performance measurement and benchmarking). Similarly, 3PL providers can learn more about the pursuable strategies and their impact in terms of value for shippers. This insight into the 3PLs value creation mechanisms can help the 3PL providers to improve their services and the way in which their offer is structured. These results offer a roadmap for 3PL providers wishing to fulfil the different shippers' needs. The proposed value creation models suggest the set of strategies that 3PL providers can follow to offer different competitive advantages to the market. For instance, the Volume-oriented approach shows that there are many strategies for achieving economies of scale and, therefore, to offer greater efficiency to shippers.

\section{Conclusions}

The paper presents the results of an exploratory study on how 3PL providers' business models can be defined by focusing on their value creation architecture. Starting from the extant literature, the aim of the research is to fill some notable gaps that had been identified and provide new valuable insights from both the academic and the managerial perspective. First, it offers a clear and comprehensive classification of 30 operational strategies that 3PL providers can pursue when defining their value proposition, together with the related factors enabling value to be created for shippers. This result is particularly valuable, as the logistics managers' perspective is also included. Second, the study outlines three main value creation models that can be followed by 3PL providers which can provide different competitive advantages for shippers, these being the volume-oriented 3PL providers, the process-oriented 3PL providers and the innovation-oriented 3PL providers.

This study has some limitations that should be taken into account. First, the empirical research was limited to companies operating in Italy. For this reason, it is not possible to know whether 3PL providers set their strategies differently according to the country they operate in, but it is 
worth noting that it offers interesting insights into how 3PL providers can organise themselves, and this can be a springboard for further research. Second, although this study presents an important picture of the current state of the market, it does not take into account that 3PL providers' business models evolve over time and that, especially for large-sized companies, 3PL providers may adopt more than one model to compete on the market (for example, by owning different business units).

Nevertheless, this study represents a first step towards a new investigation area that has not been studied in depth yet, which potentially has a strong impact for both academics and practitioners.

Building upon the results of our study, further research may additionally investigate the 3PL providers' business models, for instance, by conducting a quantitative survey to test the evidence that emerged. Future analysis may also entail learning more about the contextual variables that influence whether and how the identified models are adopted. This analysis can be also extended to a performance analysis where the aim is to understand whether and how the contextual variables can affect model performance and, potentially, understand whether one value creation model performs better than the others, and in what way.

Finally, this stream of research - to highlight the differences among 3PL providers - paves the way for future research from both the shippers' and 3PL providers' perspectives. On the one hand, future research can examine the 3PL buying process, taking into account how shippers use knowledge about 3PL providers' business models to choose the provider that is best suited to their needs and requirements. On the other hand, this research stream can possibly provoke an increase in the number of works on the quantitative assessment of efficiency and effectiveness of different 3PL providers' business models under different operational contexts. 


\section{References}

- Aghazadeh, S.M. (2003), "How to choose an effective Third Party Logistics Provider", Management Research News, Vol. 26 No. 7, pp. 50-58.

- Alexander, M. and Young, D. (1996), “Outsourcing: where's the value?", Long Range Planning, Vol. 29 No. 5, pp. 728-730.

- Anderson, S., Pearo, L.K. and Widener, S.K. (2008), "Drivers of service satisfaction: linking customer satisfaction to the service concept and customer characteristics", Journal of Service Research, Vol. 10 No. 4, pp. 365-81.

- Auramo, J., Kauremaa, J. and Tanskanen, K. (2005), "Benefits of IT in supply chain management: an explorative study of progressive companies", International Journal of Physical Distribution and Logistics Management, Vol. 35 No. 2, pp. 82-100.

- Belcourt, M. (2006), "Outsourcing - The benefits and the risks", Human Resource Management Review, Vol. 16 No. 2, pp. 269-279.

- Berglund, M., van Laarhoven, P., Sharman, G. and Wandel, S. (1999), "Third-Party Logistics: is there a future?", International Journal of Logistics Management, Vol. 10 No. 1, pp. 59-70.

- Bhatnagar, R., Sohal, A.S. and Millen, R. (1999), "Third party logistics services: a Singapore perspective", International Journal of Physical Distribution and Logistics Management, Vol. 29 No. 9, pp. 569-587.

- Bolumole, Y.A. (2003), "Evaluating the supply chain role of Logistics Service Providers", International Journal of Logistics Management, Vol. 14 No. 2, pp.93-107.

- Bowen, D. E., and Jones, G. R. (1986), "Transaction cost analysis of service organizationcustomer exchange", Academy of Management Review, Vol. 11 No. 2, pp. 428-441.

- Bryce, D.J. and Useem, M. (1998), "The impact of corporate outsourcing on company value", European Management Journal, Vol. 16 No. 6, pp. 635-643.

- Bryman, A. and Bell, M. (2011), Business Research Methods - 3rd Edition, Oxford University Press, New York.

- Carbone, V., Stone, M.A. (2005), "Growth and relational strategies used by the European logistics service providers: rationale and outcomes", Transportation Research Part E, Vol. 41 No. 6, pp. 495-510.

- Coase, R. H. (1937), “The Nature of the Firm”, Economica, Vol. 4 No. 16, pp. 386-405.

- Deepen, J.M., Goldsby, T.J. and Knemeyer, A.M. (2008), "Beyond expectations: an examination of logistics outsourcing goal achievement and goal exceedance", Journal of Business Logistics, Vol. 29 No. 2, pp. 75-105.

- Dubois, A. and Gadde, L.-E. (2002), "Systematic combining: an abductive approach to case research", Journal of Business Research, Vol. 55 No. 7, pp. 553-560.

- Efendigil, T., Önüt, S. and Kongar, E. (2008), "A holistic approach for selecting a thirdparty reverse logistics provider in the presence of vagueness", Computers and Industrial Engineering, Vol. 54 No. 2, pp. 269-287.

- Eisenhardt, K.M. and Sull, D.L. (2001), "Strategy and simple rules", Harvard Business Review, Vol. 79 No. 1, pp. 107-116.

- Ellram, L. (1996), “The use of case study method in logistics research", Journal of Business

- Logistics, Vol. 17 No. 2, pp. 93-138.

- Fink, A. (2003), The survey handbook. Sage, Thousand Oaks, CA.

- Glaser, B.G. and Strauss, A.L. (1967), The Discovery of Grounded Theory: Strategy for Qualitative Research, Aldine, Chicago.

- Hedman, J. and Kalling, T. (2003), "The business model concept: theoretical underpinnings and empirical illustrations", European Journal of Information Systems, Vol. 12, pp. 49-59.

- Hertz, S. and Alfredsson, M. (2003), "Strategic development of third party logistics providers", Industrial Marketing Management, Vol. 32 No. 2, pp. 139-149. 
- Hsiao, H.I., Kemp, R.G.M., van der Vorst, J.G.A.J. and Omta, S.W.F. (2010), "A classification of logistic outsourcing levels and their impact on service performance: Evidence from the food processing industry", International Journal of Production Economics, Vol. 124 No. 1, pp. 75-86.

- Jansen, H. (2010), "The logic of qualitative survey research and its position in the field of social research methods", Forum: Qualitative Social Research, Vol. 11 No. 2, http://nbnresolving.de/urn:nbn:de:0114-fqs1002110.

- Jharkharia, S. and Shankar, R. (2007), "Selection of logistics service provider: An analytic network process (ANP) approach", Omega, Vol. 35 No. 3, pp. 274-289.

- Kirkeby, O. (1994), “Abduktion”, In: Andersen H, editor. Videnskabsteori og metodelaere. Frederiksberg: Samfundslitteratur, pp. 122-52.

- Kremic, T., Tukel, O.I. and Rom W.O. (2006), "Outsourcing decision support: a survey of benefits, risks, and decision factors", Supply Chain Management: An International Journal, Vol. 11 No. 6, pp. 467-482.

- van Laarhoven, P., Berglund, M. and Peters, M. (2000), "Third-party logistics in Europe five years later", International Journal of Physical Distribution and Logistics Management, Vol. 30 No. 5, pp. 425-442.

- Lai, K.H., Cheng, T.C.E. and Yeung, A.C.L. (2004), “An empirical taxonomy for Logistics Service Providers", Maritime Economics and Logistics, Vol. 6 No. 4, pp. 199-219.

- Large, R.O., Kramer, N. and Hartmann, R. C. (2011), "Customer-specific adaptation by providers and their perception of 3PL-relationship success", International Journal of Physical Distribution and Logistics Management, Vol. 41 No. 9, pp. 822-838.

- Leung, L. (2015), "Validity, reliability, and generalizability in qualitative research", Journal of Family Medicine and Primary Care, Vol. 4 No. 3, pp. 324-327.

- Lieb, R. and Bentz, B.A. (2005), "The North American Third Party Logistics Industry in 2004: the Provider CEO Perspective", International Journal of Physical Distribution and Logistics Management, Vol. 35 No. 8, pp. 595-611.

- Lieb, R.C., Millen, R.A. and Van Wassenhove, L. (1993), “Third-party Logistics Services: a comparison of experienced American and European manufacturers", International Journal of Physical Distribution and Logistics Management, Vol. 23 No. 6, pp. 35-44.

- Lin, Y., Pekkarinen, S. and Ma, S. (2015), "Service-dominant logic for managing the logistics-manufacturing interface: a case study", International Journal of Logistics Management, Vol. 26 No. 1, pp. 195-214.

- Logan, M. S. (2000), "Using agency theory to design successful outsourcing relationship", International Journal of Logistics Management, Vol. 11 No. 2, pp. 21-32.

- Mele, C. (2009), "Value innovation in B2B: learning, creativity, and the provision of solutions within service-dominant logic", Journal of Customer Behavior, Vol. 8 No. 3, pp. 199-220.

- Min, H., Demond, S. and Joo, S. (2013), "Evaluating the comparative managerial efficiency of leading third party logistics providers in North America", Benchmarking: An International Journal, Vol. 20 No. 1, pp. 62-78.

- Penrose, E.T. (1959), The Theory of the Growth of the Firm, Wiley, New York.

- Persson, G. and Virum, H. (2001), "Growth strategies for Logistics Service Providers: a case study", International Journal of Logistics Management, Vol. 12 No. 1, pp. 53-64.

- Prock1, G., Pflaum, A. and Herbert, K. (2012), "3PL factories or lernstatts? Value-creation models for 3PL service providers", International Journal of Physical Distribution and Logistics Management, Vol. 42 No. 6, pp. 544-561.

- Quinn, J.B. (1999), "Strategic outsourcing: leveraging knowledge capabilities", MIT Sloan Management Review, Vol. 40 No. 4, pp. 9-21. 
- Quinn, J. B. and Hilmer, F. G. (1995), "Strategic outsourcing. By assessing the relative costs and risks of making or buying, companies can leverage their skills and resources for increased profitability", The McKinsey Quarterly, No.1, pp. 48-70.

- Rabinovich, E., Windle, R., Dresner, M. and Corsi, T. (1999), "Outsourcing of integrated logistics functions: an examination of industry practices", International Journal of Physical Distribution and Logistics Management, Vol. 29 No. 6, pp. 353-373.

- Rao, K. and Young, R.R. (1994), "Global supply chains: factors influencing outsourcing of logistics functions", International Journal of Physical Distribution and Logistics Management, Vol. 24 No. 6, pp. 11-19.

- Razzaque, M.A. and Sheng, C.C. (1998), "Outsourcing of logistics functions: a literature survey", International Journal of Physical Distribution and Logistics Management, Vol. 28 No. 2, pp. 89-107.

- Ruggero, S. (2008), "Caratteri e tendenze evolutive del business model dei Logistics Service Provider", available on-line at: http://www.impresaprogetto.it/sites/impresaprogetto.it/files/articles/ip_108_wp_ruggiero.p df

- Sampson, S.E. and Froehle, C.M. (2006), "Foundations and Implications of a Proposed Unified Services Theory", Production and Operations Management, Vol. 15 No. 2, pp. 329343.

- Selviaridis, K. and Norman, A. (2015), "Performance-based contracting for advanced logistics services: challenges in its adoption, design and management", International Journal of Physical Distribution and Logistics Management, Vol. 45 No. 6, pp. 592-617.

- Selviaridis, K. and Spring, M. (2007), "Third Party Logistics: a literature review and research agenda", International Journal of Logistics Management, Vol. 18, No. 1, pp.125150.

- Shafer, S.M., Smith, H.J. and Linder, J.C. (2005), “The power of business models”, Business Horizons, Vol. 48 No. 3, pp. 199-207.

- Skjoett-Larsen, T. (2000), "Third Party Logistics - from an interorganizational point of view", International Journal of Physical Distribution and Logistics Management, Vol. 30 No. 2, pp. 112-127.

- Sum, C.C. and Teo, C.B. (1999), "Strategic posture of logistics service providers in Singapore", International Journal of Physical Distribution and Logistics Management, Vol. 29 No. 9, pp. 588-605.

- Vargo, S.L. and Lusch R.F. (2008), "Service-dominant: continuing the evolution", Journal of the Academy of Marketing Science, Vol. 36 No. 1, pp. 1-10.

- Vargo, S.L., Maglio, P.P. and Akaka, M.A. (2008), "On value and value co-creation: a service systems and service logic perspective", European Management Journal, Vol. 26, pp. 145-152.

- Wallenburg, C.M. (2009), "Innovation in logistics outsourcing relationships: proactive improvement by logistics service providers as a driver of customer loyalty", Journal of Supply Chain Management, Vol. 45, No. 2, pp. 75-93.

- Wang, X., Persson, G. and Huemer, L. (2016), "Logistics Service Providers and value creation through collaboration: a case study", Long Range Planning, Vol. 49 No. 1, pp. 117 128.

- Wilding, R. and Juriado, R. (2004), "Customer perceptions on logistics outsourcing in the European consumer goods industry”, International Journal of Physical Distribution and Logistics Management, Vol. 34, No. 8, pp. 628-644.

- Williamson, O. E. (1985), The Economic Institutions of Capitalism, The Free Press, New York. 
- Yazdanparast, A., Manuj, I. and Swartz, S.M. (2010), "Co-creating logistics value: a servicedominant logic perspective”, International Journal of Logistics Management, Vol. 21 No. 3, pp. 375-403.

- Yeung, J.H.Y., Selen, W., Sum C.C. and Huo, B. (2006), "Linking financial performance to strategic orientation and operational priorities: an empirical study of Third-Party Logistics Providers", International Journal of Physical Distribution and Logistics Management, Vol. 36 No. 3, pp. 210-230.

- Yin, R. (1994), Case Study Research: Design and Methods, 2nd ed., Sage Publishing, Beverly Hills, CA.

- Ying, W. and Dayong, S. (2005), "Multi-agent framework for third party logistics in Ecommerce", Expert Systems with Applications, Vol. 29 No. 2, pp. 431-436.

- Zacharia, Z.G., Sanders, N.R. and Nix, N.W. (2011), "The emerging role of the Third Party Logistics Provider (3PL) as an orchestrator", Journal of Business Logistics, Vol. 32 No. 1, pp. 40-54. 